\title{
Utility of intravascular ultrasound in the diagnosis of spontaneous coronary dissection
}

\author{
Utilidad del ultrasonido intracoronario en el diagnóstico de disección coronaria \\ espontánea
}

\author{
Nelson Amores and Paúl Salvador* \\ Department of Cardiology, Hospital Carlos Andrade Marín. Quito, Ecuador
}

\section{Presentation of two cases}

Thirty-two-year-old female with no cardiovascular risk factors; she denied using hormonal contraceptives. She attended our department referring rest angina of approximately seven hours evolution; initial electrocardiogram showed an extensive anterior ST-elevation myocardial infarction. Coronary angiography revealed an angiographically severe lesion in the proximal anterior descending (AD) artery. In the evaluation with intracoronary ultrasound (IVUS), an area of dissection originating in the $A D$ artery middle segment was observed (Fig. 1). Transthoracic echocardiogram showed evidence of anteroseptal-apical akinesia with preserved ventricular function (59\% biplane Simpson's rule). Not performing coronary intervention and monitoring with conservative pharmacological treatment optimization was decided. Evolution was satisfactory at first and third month of follow-up, without recurrent angina or functional class decrease being observed. The patient receives acetylsalicylic acid (ASA), calcium antagonists, beta-blockers and nitrates.

Forty-year-old woman without cardiovascular risk factors; she denied using hormonal contraceptives. She attended the emergency department complaining of typical rest angina that had occurred at dawn while she was sleeping. At evaluation she was asymptomatic. Initial electrocardiogram showed an anterior subepicardial injury; minimal enzymatic mobilization. It was classified as unstable angina and a coronary angiography was performed, which identified a non-significant injury in the AD artery middle third. IVUS revealed a dissection area in the AD artery middle third (Fig. 2). Not to perform any coronary intervention was decided. Echocardiogram showed a preserved ventricular function $(66 \%$ biplane Simpson's rule), without segmental motility disorders. Her evolution has been satisfactory; she receives ASA, an angiotensin-converting enzyme inhibitor and a beta-blocker; with a follow up of four months, she is free of angina or other symptoms.

Coronary artery dissection is characterized by rupture of the coronary tunica intima, which allows the flow of blood into a false lumen in the tunica media, which obliterates the true lumen and causes coronary failure ${ }^{1-3}$.

A much higher prevalence has been observed in contemporary case report series, and it is the cause of up to $25 \%$ of all cases of acute coronary syndrome in women $<50$ years of age. However, it is deemed to

\footnotetext{
Correspondence:

*Paúl Salvador

Servicio de Cardiología

Hospital Carlos Andrade Marín

Av. Universitaria y Ayacucho, N19-63

Date of reception: 18-11-2017

Date of acceptance: 03-08-2018

E-mail: paulsalvador90@ hotmail.com

DOI: 10.24875/ACME.M19000013

Available online: 09-08-2019 Arch Cardiol Mex (Eng). 2019;89(1):76-78 www.archivoscardiologia.com 2604-7063 @ 2018 Instituto Nacional de Cardiología Ignacio Chávez. Published by Permanyer México. This is an open access article under the CC
} BY-NC-ND license (http://creativecommons.org/licenses/by-nc-nd/4.0/). 


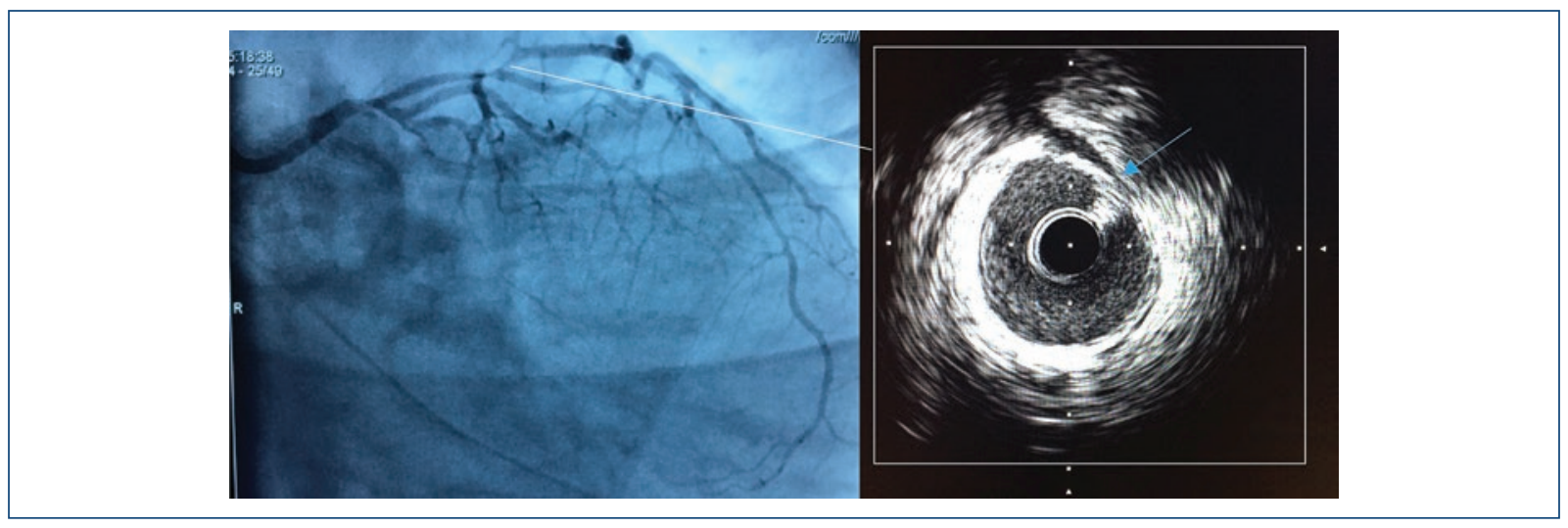

Figure 1. Coronary angiography and intracoronary ultrasound corresponding to the dissection site (anterior descending coronary artery proximal segment) with the presence of dissection flap (arrow) and intramural hematoma.

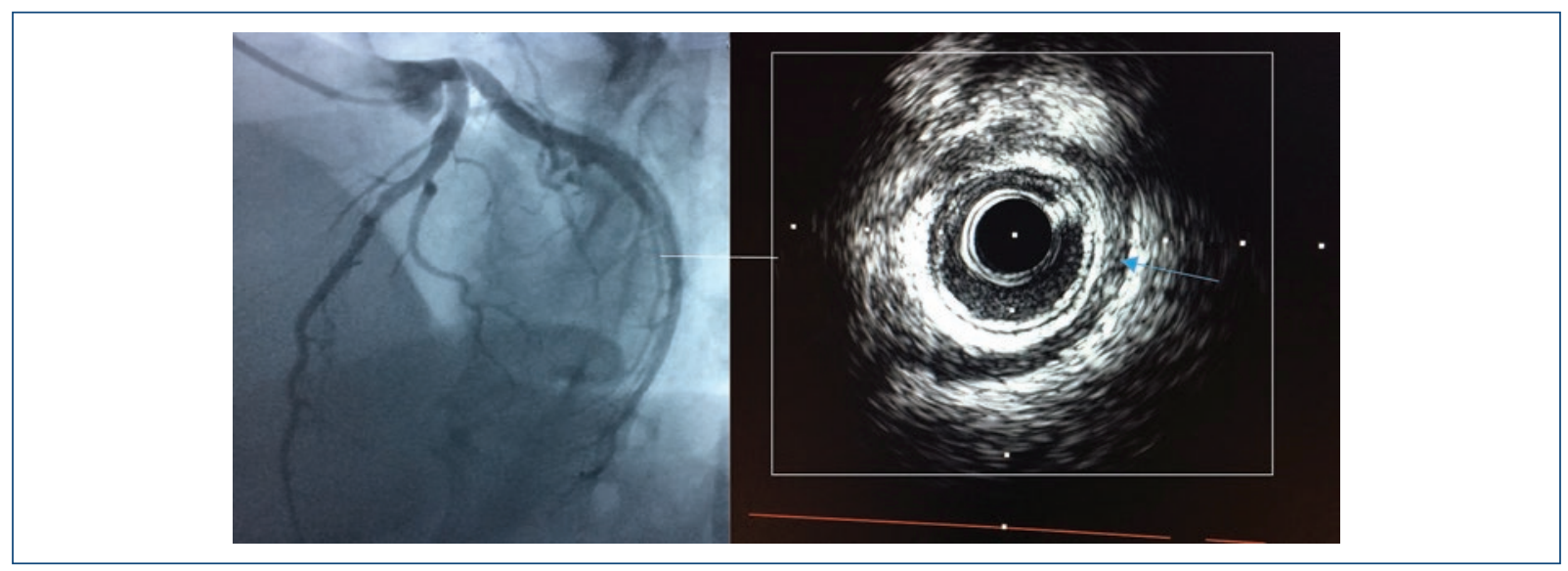

Figure 2. Coronary angiography and intracoronary ultrasound corresponding to the dissection site (anterior descending coronary artery middle to distal segment) with the presence of intramural hematoma (middle segment) (arrow).

remain underdiagnosed, owing to its low risk profile in population-based series. The development and widespread use of intracoronary imaging techniques allow higher identification of this disease, with a progressive increase in its incidence ${ }^{3}$.

Most often, it affects the female gender, with published series showing a 3:1 ratio. Other risk factors are gestational or puerperal period ${ }^{4}$, presence of coronary atherosclerosis, estrogen therapy, coexistence of systemic diseases, migraine, connective tissue diseases and, more recently, a clearer relationship with fibromuscular dysplasia has been determined ${ }^{3,4}$.

The most common presentation of this condition is as an ST-elevation myocardial infarction, which involves the anterior aspect of the left ventricle, since involvement of the anterior descending artery is much more frequent than that of other arteries ${ }^{4,5}$.
Invasive coronary angiography allows establishing the diagnosis through three types of angiographic presentation: 1) evidence of contrast extravasation creating a double lumen; 2) narrowing of the upper lumen of $20 \mathrm{~mm}$ in length, without change with nitroglycerin administration and with no evidence of atherosclerotic disease in other arteries, and 3) focal stenosis similar to an atherosclerotic lesion, which requires intracoronary imaging for confirmation 4 .

The use of IVUS and optical coherence tomography allows characterizing the lesion in fine detail, confirming the diagnosis and estimating the dissection extent. The finding of an intimal-medial dissection flap and intramural hematoma are the criteria employed ${ }^{5,6}$.

Given the low incidence and underdiagnosis of this pathology, there are not enough randomized clinical trials with adequate numbers of patients that help making 
an evidence-based decision, and the decisive analysis shall therefore be on an individual patient basis, based on: initial clinical condition, risk of bleeding, response or not to conservative treatment, anatomy of the lesion and involvement or not of several arteries ${ }^{7}$.

Various observational studies and a recent meta-analysis have shown that conservative treatment is chosen as first option, since it has shown better intra-hospital results. Percutaneous coronary intervention represents a challenge in these cases due to technical difficulty for stenting the true vessel lumen, biased quantification of the artery diameter and friability of the arterial wall at the moment of stent implantation; all of this causes an increased risk of acute and long-term complications ${ }^{8,9}$.

Different strategies have been described, including resorbable stent implantation ${ }^{10}$ and the use of cutting balloons that perform fenestrations in the vessel intima and thus relieve compression, however; more quantity and follow-up of these patients are required. In any case, the development of all these techniques has been aided by the use of intracoronary imaging, either with ultrasound or tomography ${ }^{6}$.

In relation to surgical revascularization, it has been relegated as the last therapeutic option because of the risk that entails anastomosing a bridge to the false lumen and the high incidence of re-occlusions. This option is considered when coronary interventionism fails and there is a good distal bed ${ }^{9}$.

With regard to conservative treatment, antiplatelet and anticoagulant therapy as initial strategy in the context of an acute coronary syndrome presentation is debatable after spontaneous coronary dissection diagnosis. Evidently, the use of antiaggregants is indicated when placing a stent was indicated and, on the other hand, their use for the prevention of recurrences without interventionism is uncertain. The use anticoagulation entails a risk, since it has been identified as a promoter of increased dissection, and its indication should therefore be relegated to cases where embolic risk is high, such as in thromboembolism or left ventricular mural thrombus. The use of statins is quite controversial, since, generally, these patients have no atherothrombotic component and, in addition, their use has demonstrated spontaneous coronary dissection increased recurrence, according to an observational study ${ }^{3,5,9}$.

Various authors recommend the use of beta-blockers as a treatment strategy, arguing that their use, by decreasing parietal stress, would help to reduce the dissection line; however, this recommendation has not shown a decrease in spontaneous coronary dissection recurrence ${ }^{10}$.

\section{Conflicts of interest}

The authors declare not having any conflicts of interest or having received funding.

\section{Ethical disclosures}

Protection of people and animals The authors declare that no experiments have been conducted on humans or animals for this investigation.

Confidentiality of data The authors declare having followed the protocols of their work center on the publication of patient data.

Right to privacy and informed consent The authors declare that no patient data appear in this article.

\section{Acknowledgements}

To all the Cardiology Department personnel for their invaluable support in the day-to-day of our work.

\section{References}

1. Saw J, Mancini J, Humphries K. Contemporary review on spontaneous coronary artery dissection. J Am Coll Cardiol. 2016;68(14):297-312.

2. Meng PN, Xu C, You W, Wu ZM, Xie DJ, Zhang H, et al. Spontaneous coronary artery dissection as a cause of acute myocardial infarction in young female population: A single-center study. Chin Med J (Engl). 2017;130(13):1534.

3. Tweet M, Kok S, Hayes S. Spontaneous coronary artery dissection in women: What is known and what is yet to be understood. Clin Cardiol. 2018;41(2):1-3.

4. Sánchez Rodríguez AC, Domínguez Rivas MJ, González Alemán O, Beíitez Muñoz L, Álvarez-Osorio Cisneros S, Rodríguez Yañez JC. Disección coronaria espontánea. Causa alternativa de isquemia miocárdica en mujeres. Rev. argent. ter. intensiva. 2018;35(1):1-2.

5. Saw J, Aymong E, Sedlak T, Buller CE, Starovoytov A, Ricci D, et al. Spontaneous coronary artery dissection association with predisposing arteriopathies and precipitating stressors and cardiovascular outcomes. Circ Cardiovasc Interv. 2014;7(5):645-55.

6. Hun Jang J, Hyeok Kim D, Hyuk Yang D, II Woo S, Kwan J, Soo Park K et al. Spontaneous coronary artery dissection by intravascular ultrasound in a patient with myocardial infarction. Korean J Intern Med. 2014;29: 106-10.

7. Bastante T, Cuesta J, García-Guimaraes M, Rivero F, Maruri R, Adlan D, et al. Current management of spontaneous coronary artery dissection. Expert Rev Cardiovasc Ther. 2017;15(8):619-28.

8. Tweet M, Eleid MF, Best PJM, Lennon RJ, Lerman A, Rihal CS, et al. Spontaneous coronary artery dissection: Revascularization versus conservative therapy. Circ Cardiovasc Interv. 2014;7(6):777-86.

9. Martins JL, Afreixo V, Santos L, Costa M, Santos J, Gonçalves L. Medical treatment or revascularisation as the best approach for spontaneous coronary artery dissection: A systematic review and meta-analysis. Eur Hear J Acute Cardiovasc Care. 2018;7(7):614-23.

10. Mahmood MM, Austin D. IVUS and OCT guided primary percutaneous coronary intervention for spontaneous coronary artery dissection with bioresorbable vascular scaffolds. Cardiovasc Revascularization Med. 2017;18(1):53-7. 